\title{
Assessment of occupational health and safety risks in a Turkish public hospital using a two-stage hesitant fuzzy linguistic approach
}

\author{
Aslı Çalış Boyacı ${ }^{1}\left[\right.$ ] Aslı Selim² ${ }^{2}$ \\ Received: 8 July 2021 / Accepted: 14 December 2021 / Published online: 21 January 2022 \\ (c) The Author(s), under exclusive licence to Springer-Verlag GmbH Germany, part of Springer Nature 2021
}

\begin{abstract}
Occupational health and safety (OHS) risk assessment studies have gained importance recently as a result of increasing occupational accidents and occupational diseases. The health sector has a greater risk than many sectors for occupational accidents and occupational diseases. Although the health sector is one of the priority sectors in Turkey, OHS practices have not been fully implemented in this field. For this reason, this study adopts a two-stage approach to assess the OHS risks in the health sector by combining the Fine-Kinney and multi-criteria hesitant fuzzy linguistic term set (HFLTS) methods. The proposed method was applied to the OHS risks in the operating room of a public hospital in Turkey. As a solution to the problem, first, the potential hazards and related risks in the operating room were determined by the experts. In this first stage, 44 hazards were determined from the opinions of experts and records of past incidents. Parameter weights were then determined using the multi-criteria HFLTS method. The multi-criteria HFLTS method was used to evaluate seven hazards to be categorized as substantial-risk or higher according to the Fine-Kinney method, taking into account parameter weights. Sensitivity analysis was then carried out. Finally, actions were taken to mitigate the risks.
\end{abstract}

Keywords Occupational health and safety $\cdot$ Risk assessment $\cdot$ Public hospital $\cdot$ Fine-Kinney $\cdot$ Hesitant fuzzy linguistic term sets

\section{Introduction}

Hazard is one of the most important concepts in occupational health and safety (OHS). It comprises a set of investigations and practices designed to ensure the protection of employees. It identifies any situation that exists in the workplace or impact from the outside that has the potential to cause injury, disease, or death, or to damage property, material, or the workplace environment as a hazard. Risk is the possibility or the likelihood of death, injury, illness, or other harmful consequences that may result from a hazard. The

Responsible Editor: Lotfi Aleya

Aslı Çalış Boyacı

asli.calis@omu.edu.tr

1 Department of Industrial Engineering, Faculty of Engineering, Ondokuz Mayıs University, 55139 Samsun, Turkey

2 Department of Intelligent Systems Engineering, Institute of Graduate Studies, Ondokuz Mayıs University, 55139 Samsun, Turkey comprehensive study conducted to estimate the magnitude of the risk arising from the hazard and to decide whether the risk is acceptable taking into account the adequacy of the existing controls is described as the risk assessment (HSA 2006). OHS risk assessment techniques are divided into two categories: qualitative and quantitative. In qualitative techniques, a numerical value is assigned to each parameter, such as the probability and severity of the hazard. These values may be processed by mathematical and logical methods and a risk value calculated. A list of qualitative and quantitative techniques can be found in Ilbahar et al. (Ilbahar et al. 2018).

OHS risk assessment studies have recently gained importance as a result of the increase in occupational accidents and occupational disease due to technological developments and the industrialization process. In 2017, there were over 3.3 million non-fatal accidents and 3552 fatal accidents in the EU-28 (Eurostat 2019). Turkey is placed near the top in terms of occupational accidents in Europe and the world and ranks first in fatal accidents in Europe. In Turkey, in 2016, there were 286,068 occupational accidents, and 1405 employees lost their life as a result of occupational accidents and disease, 36 of whom were women and 1369 were men 
(MMO 2018). In Turkey, the health sector has a high risk for occupational accidents and occupational disease. Hospitals are the largest sector of healthcare. For this reason, this study undertook a comprehensive study on OHS risk assessment in the hospital. The study utilizes an approach that combines Fine-Kinney and multi-criteria hesitant fuzzy linguistic term set (HFLTS) for OHS risk assessment. The proposed approach has been applied to the operating room of a public hospital in Turkey. First, hazards were identified, and a risk assessment was then undertaken on the 44 hazards determined using the Fine-Kinney method. Multi-criteria HFLTS was used to determine the parameter weights and to prioritize the hazards and their related risks that are rated as substantial or higher. Finally, these hazards were ranked, and control measures were proposed and implemented to mitigate the hazards.

OHS risk assessment studies in the literature can be summarized as follows. Leigh and Miller examined the jobrelated diseases of workers and the occupations related to those diseases (Leigh and Miller 1998). Larsson and Field analyzed the occupational injury incidence and severity, and they calculated the relative distribution of occupational injury risks in Victoria (Larsson and Field 2002). Macedo and Silva analyzed the occupational accidents in work environments in Portugal. The most important economic activities in terms of occupational accidents were construction and manufacturing (Macedo and Silva 2005). Chen et al. administered a survey to evaluate the occupational health and safety management systems (OHSMSs) and examine important performance indicators in the printed circuit board industry in Taiwan (Chen et al. 2009). Morillas et al. provided a comparative analysis of OHS risk prevention practices in Sweden and Spain (Morillas et al. 2013). Sousa et al. proposed a quantitative model that conducts cost-benefit analysis for OHS risk management in the construction industry (Sousa et al. 2015). Bayatian et al. applied a dynamic model for risk assessment of occupational exposure to benzene (Bayatian et al. 2018). Mohammadyan et al. performed health risk assessment of occupational exposure to styrene in the electronic industries (Mohammadyan et al. 2019a). Abad et al. built a Bayesian model for occupational health surveillance in workers exposed to silica (Abad et al. 2019). Mohammadyan et al. carried out quantitative and semiquantitative risk assessment of occupational exposure to lead among electrical solderers (Mohammadyan et al. 2019b). Jalali et al. performed a risk assessment for occupational exposure to formaldehyde (Jalali et al. 2021). Rachidi et al. launched a qualitative and quantitative study to assess occupational risks in the food industry in Morocco during the COVID-19 pandemic (Rachidi et al. 2021).

OHS risk assessment generally consists of gathering information, identifying hazards, quantifying the risks associated with those hazards, and assessing the severity of those risks. Fuzzy logic and multi-criteria decision-making (MCDM) methods have been used in OHS to overcome the deficiencies in traditional risk assessment approaches to determine the relationships between the factors and their effects on the risks. Murè et al. presented a risk assessment method based on fuzzy logic to assess the risks of occupational accidents (Murè et al. 2006). Gürcanli and Müngen proposed an occupational safety risk analysis approach using fuzzy sets (Gürcanli and Müngen 2009). Grassi et al. proposed a fuzzy multi-attribute risk evaluation model for safety in workplaces (Grassi et al. 2009). Liu and Tsai developed a risk assessment method that combines QFD, fuzzy ANP, and fuzzy FMEA for the construction industry (Liu and Tsai 2012). Mahdevari et al. proposed a model based on fuzzy TOPSIS to assess the OHS risks in underground coal mines in Iran (Mahdevari et al. 2014). Liu et al. suggested a model for evaluating the risk of failure modes based on fuzzy logic and the MULTIMOORA method for a healthcare facility (Liu et al. 2014). Ghasemi and Talebi Brijani proposed a risk management framework for flexible manufacturing system selection decisions using fuzzy AHP-PROMETHEE integrated approach (Ghasemi and Talebi Brijani 2014). Dağsuyu et al. utilized the classical and fuzzy FMEA for risk analysis in a sterilization unit (Dağsuyu et al. 2016). Chang et al. evaluated the marketability of certificates for OHS management in Taiwan using fuzzy AHP, fuzzy ANP, and VIKOR methods (Chang et al. 2016). Kokangül et al. conducted a risk analysis in a manufacturing company using AHP and Fine-Kinney methods (Kokangül et al. 2017). İnan et al. built a multiple attribute decision-making model to determine and compare the OHSMS performances of the firms (İnan et al. 2017). Gul et al. proposed a model based on fuzzy AHP and fuzzy VIKOR methods for OHS risk assessment in hospitals (Gul et al. 2017). Gul and Ak used Pythagorean fuzzy AHP and fuzzy TOPSIS to quantify risk ratings in OHS risk assessment (Gul and Ak 2018). Ilbahar et al. proposed an integrated approach including Pythagorean fuzzy AHP and fuzzy inference system for OHS risk assessment (Ilbahar et al. 2018). Gul and Celik proposed a risk assessment approach that includes a combination of Fine-Kinney and a fuzzy rule-based expert system for rail transportation systems (Gul and Celik 2018). Mohandes and Zhang developed a comprehensive hybrid fuzzybased occupational risk assessment model for construction workers (Mohandes and Zhang 2019). Stefanović et al. ranked the workplaces in terms of risk assessment using the PROMETHEE method (Stefanović et al. 2019). Khan et al. proposed a model based on modified-SIRA and fuzzy TOPSIS methods for OHS risk assessment in the construction industry in Pakistan (Khan et al. 2019). Liu et al. used integrated SWARA-MABAC model under bipolar fuzzy environment for OHS risk assessment (Liu et al. 2020). Gul and Ak proposed a new integrated approach using fuzzy 
BWM and fuzzy MAIRCA for occupational risk assessment (Gul and Ak 2020). Tang et al. developed risk prioritization method for Fine-Kinney using generalized TODIM, BWM, and interval type-2 fuzzy set (Tang et al. 2021). Khalilzadeh et al. used the fuzzy SWARA, FMEA, PROMETHEE approaches, and multi-objective programming model for risk assessment in the planning phase of the oil and gas construction projects in Iran (Khalilzadeh et al. 2021). Liu et al. developed an OHS risk assessment framework by integrating TODIM and PROMETHEE methods under linguistic spherical fuzzy environment (Liu et al. 2021).

HFLTS has been applied successfully to various study areas that include performance evaluation, supplier selection, healthcare risk analysis, site selection, and selection of health tourism strategy (Table 1). The current study contributes to the literature on OHS risk assessment in the following aspects:

(1) HFLTS reduces the difficulty that decision makers experience in defining linguistic terms and provides flexibility in their evaluations

(2) HFLTS allows decision makers to assign a weight to parameters (unlike Fine-Kinney and other classical OHS risk assessment techniques)

(3) According to the authors' best knowledge, there are no studies that combine Fine-Kinney and multi-criteria HFLTS methods for OHS risk assessment in the health sector. This study aims to fill this gap.

Table 1 Summary of HFLTS studies in the literature

\begin{tabular}{|c|c|c|c|}
\hline Author and year & Method & Objective & Type \\
\hline Rodríguez et al., 2012 & HFLTS & Method proposal & Illustrative \\
\hline Beg and Rashid, 2013 & HFLTS, TOPSIS & Method proposal & Illustrative \\
\hline Liao et al., 2014 & HFLTS & Evaluation of the quality of movies & Illustrative \\
\hline Liu and Rodríguez, 2014 & HFLTS, Fuzzy TOPSIS & Supplier selection & Illustrative \\
\hline Liao and $\mathrm{Xu}, 2015$ & HFLTS, TOPSIS, VIKOR & Selection of an ERP system & Illustrative \\
\hline Montes et al., 2015 & HFLTS & Development of a web tool for the housing market & Case Study \\
\hline Wang et al., 2015 & HFLTS, ELECTRE & Method proposal & Illustrative \\
\hline Wei et al., 2015 & HFLTS, TODIM & Evaluation of the telecommunications service providers & Illustrative \\
\hline Yavuz et al., 2015 & Multi-criteria HFLTS & Evaluation of alternative-fuel vehicles & Case Study \\
\hline Chen et al., 2016 & Proportional HFLTS (PHFLTS) & Evaluation of the university faculty & Illustrative \\
\hline $\mathrm{Da}$ and $\mathrm{Xu}, 2016$ & HFLTS & Urban waterfront redevelopment & Case Study \\
\hline Fahmi et al., 2016 & HFLTS, ELECTRE I & Supplier selection & Illustrative \\
\hline Liu et al., 2016 & HFLTS, FMEA & Healthcare risk analysis & Case Study \\
\hline Gou et al., 2017 & $\begin{array}{l}\text { Double hierarchy HFLTS } \\
\text { (DHHFLTS), MULTI- } \\
\text { MOORA }\end{array}$ & $\begin{array}{l}\text { Evaluation of the implementation status of haze controlling } \\
\text { measures }\end{array}$ & Case Study \\
\hline Khishtandar et al., 2017 & HFLTS & Assessment of bioenergy production technologies & Case Study \\
\hline Tüysüz and Şimşek, 2017 & HFLTS, AHP & Performance evaluation & Case Study \\
\hline Adem et al., 2018 & HFLTS, SWOT & $\begin{array}{l}\text { Assessment of occupational safety risks in the life cycle of } \\
\text { wind turbine }\end{array}$ & Case Study \\
\hline Feng et al., 2018 & HFLTS, PROMETHEE & Facility location selection & Illustrative \\
\hline Liao et al., 2018 & HFLTS, ELECTRE II & Method proposal & Illustrative \\
\hline Huang et al., 2019 & PHFLTS, QFD & Method proposal & Illustrative \\
\hline Wu et al., 2019 & HFLTS, VIKOR, TOPSIS & Method proposal & Illustrative \\
\hline Çalış Boyacı, 2020 & HFLTS, ARAS & Selection of eco-friendly cities & Case Study \\
\hline Wang et al., 2020 & HFLTS, GIA & Resource allocation in water pollution treatment & Illustrative \\
\hline Büyüközkan and Güler, 2020 & HFLTS, SAW, ARAS & Smart watch evaluation & Case Study \\
\hline Çalış Boyacı et al., 2021 & HFLTS, TOPSIS, GIS & $\begin{array}{l}\text { Site selection for waste vegetable oil and waste battery col- } \\
\text { lection boxes }\end{array}$ & Case Study \\
\hline Rodríguez et al., 2021 & HFLTS, CRP & Method proposal & Illustrative \\
\hline Büyüközkan et al., 2021 & \multicolumn{2}{|c|}{ HFLTS, SWOT, AHP, MABAC Health tourism strategy selection } & Case Study \\
\hline Ghorui et al., 2021 & HFLTS, TOPSIS, Fuzzy AHP & $\begin{array}{l}\text { Identification of dominant risk factor involved in spread of } \\
\text { COVID-19 }\end{array}$ & Case Study \\
\hline
\end{tabular}




\section{Methodology}

This study investigates the combination of the Fine-Kinney and multi-criteria HFLTS methods for OHS risk assessment. These two methods are explained in detail in this section.

\section{Fine-Kinney method}

The Fine-Kinney risk assessment method was first proposed by Fine in 1971 as a mathematical assessment method for hazard control (Fine 1971). Kinney and Wiruth further developed the method in 1976 and transformed its application from a mathematical approach to a graphical approach (Kinney and Wiruth 1976). In this method, a risk score $(R)$ is calculated by multiplying the probability $(P)$, frequency $(F)$, and severity $(S)$ of a potential hazard, and this score is then mapped to a risk scale and the requirement for mitigation. It is formulated as follows:

$R=P \times F \times S$

The risk scale and requirement for mitigation are given in Table 2 (Kinney and Wiruth 1976).

\section{Multi-criteria HFLTS method}

Uncertain knowledge is effectively dealt with using fuzzy logic and fuzzy set theory. However, when two or more sources of uncertainty exist at the same time, fuzzy sets are constrained (Rodríguez et al. 2012). Hesitant fuzzy sets, which allow us to describe situations in which different membership functions are considered possible, are a generalization of fuzzy sets. They can overcome the difficulties in deciding the membership degree of an element (Torra 2010). In traditional fuzzy linguistic approaches, a single expression should be chosen to restrict the experts. Experts, on the other hand, may hesitate to use suitable linguistic expressions (Onar et al. 2016). When experts hesitate between several linguistic expressions, they can use HFLTS.

Rodríguez et al. suggested a hesitant linguistic group decision-making model with a single-criterion (Rodríguez et al. 2013). This algorithm was extended by Yavuz et al. to consider a multi-criteria decision-making problem, and

Table 2 Risk scale (Kinney and Wiruth 1976)

\begin{tabular}{ll}
\hline Risk score & Situation \\
\hline$>400$ & Very high risk (consider discontinuing operation) \\
200 to 400 & High risk (immediate correction required) \\
70 to 200 & Substantial risk (correction needed) \\
20 to 70 & Possible risk (attention indicated) \\
$<20$ & Risk (perhaps acceptable) \\
\hline
\end{tabular}

the steps of the suggested algorithm are as follows (Yavuz et al. 2015):

Step 1. The semantics and syntax of the linguistic term set $S$ are defined using Eq. (2) (Rodríguez et al. 2013).

$$
S=\left\{\begin{array}{c}
\text { no importance }(n), \text { very lowimportance }(v l), \\
\text { low importance }(l), \text { medium importance }(m), \\
\text { high importance }(h), \\
\text { very high importance }(v h), \\
\text { absolute importance }(a)
\end{array}\right\}
$$

Step 2. A context-free grammar $G_{H}$ is defined, where $G_{H}=\left\{V_{N}, V_{T}, I, P\right\}$ and $V_{N}$ is the set of nonterminal symbols, $V_{T}$ is the set of terminals' symbols, $I$ is the starting symbol, and $P$ is the production rules that are defined in an extended Backus-Naur form (Rodríguez et al. 2012). Step 3. The preference relations $p^{k}$ for both criteria and alternatives are elicited from the experts.

Step 4. The preference relations are transformed into HFLTS.

Step 5. The envelopes $\left[p_{i j}^{k-}, p_{i j}^{k+}\right]$ are obtained for each HFLTS.

Step 6. A linguistic aggregation operator $(\varphi)$ is selected, and the pessimistic and optimistic collective preference relations $\left(P_{C}^{-}, P_{C}^{+}\right)$are obtained. The arithmetic mean given in Eq. (3) is used for $\varphi$ :

$$
\bar{x}=\Delta\left(\frac{1}{n} \sum_{i=1}^{n} \Delta^{-1}\left(s_{i}, \alpha_{i}\right)\right)=\Delta\left(\frac{1}{n} \sum_{i=1}^{n} \beta_{i}\right) .
$$

Step 7. The pessimistic and optimistic collective preferences for the alternatives are calculated from $\varphi$.

Step 8 . The vector of the intervals for the collective preferences is built.

Step 9. The obtained interval utilities are normalized.

Step 10. The weighted scores are calculated.

\section{Implementation of the proposed approach}

The application of the proposed method is described in detail in the following sections. The methodology is shown in diagrammatic form in Fig. 1. The method comprises three phases: preparation, analysis, and proposals for mitigation.

\section{Problem definition}

The proposed risk assessment method was applied to the operating room of a public hospital in Turkey. Three experts, who are responsible for the operation and OHS procedures and policies of the unit, took part in the analysis process. 
Fig. 1 Framework of the proposed approach

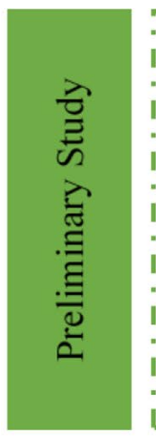

Phase I: Preparation
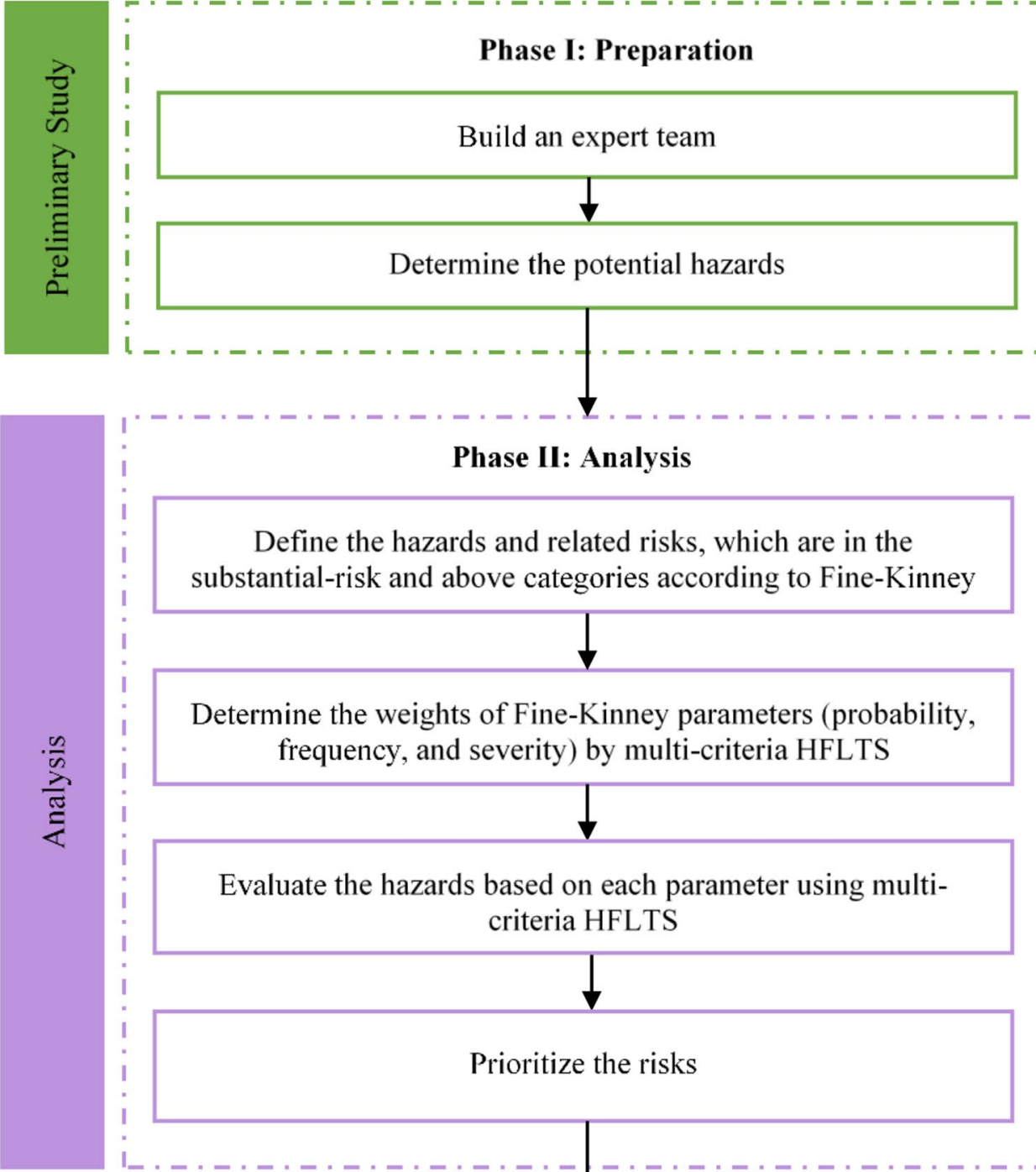

Phase II: Analysis

Define the hazards and related risks, which are in the substantial-risk and above categories according to Fine-Kinney

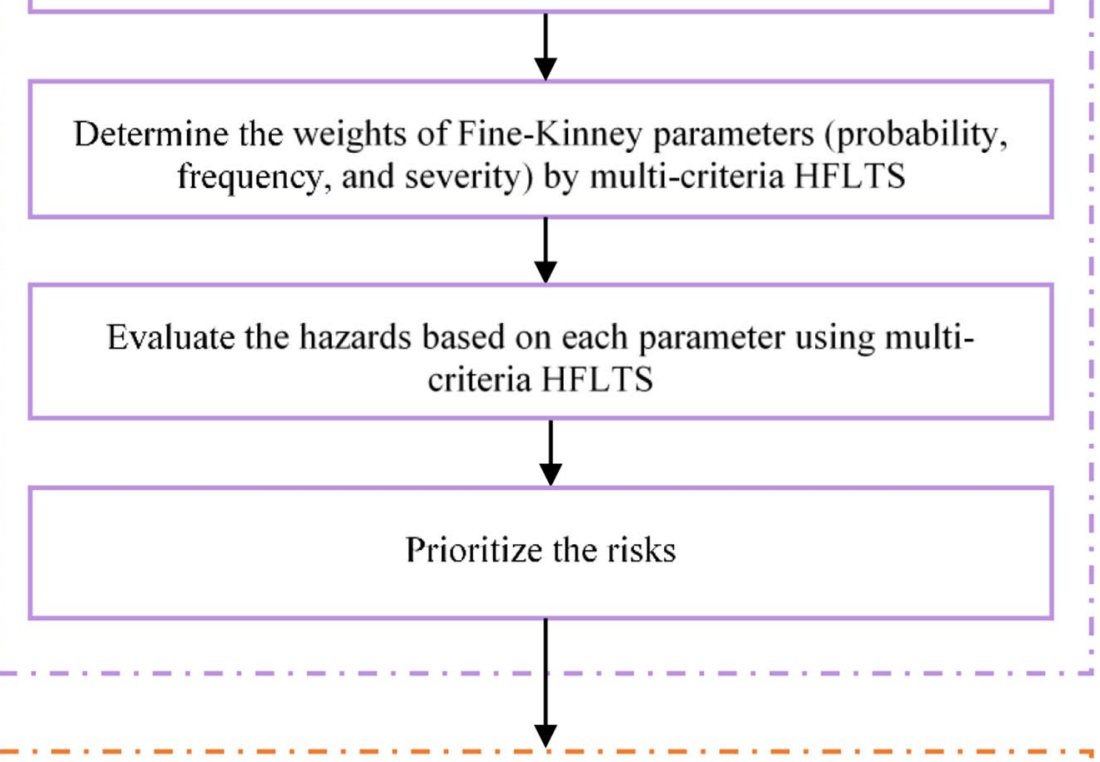

Phase III: Control measures

Take the control measures for associated risk
Expert 1 is an OHS specialist, Expert 2 is an operating room supervisor, and Expert 3 is an operating room nurse. The experts have 7, 25, and 20 years of experience respectively. Following the process, all potential hazards and their related risks in the operating room were first determined by the experts. Forty-four (44) hazards including, "Exposed electrical installation elements," "Improper storage of chemicals," "Storage of waste in unsuitable containers," "Exposure to radiation," and "Not preparing an emergency plan," were identified based on the opinion of the experts and from records of past incidents.

\section{Analysis}

\section{Prioritization of the risks using the Fine-Kinney method}

After the potential hazards and their respective risks were identified, the risks were prioritized using the Fine-Kinney method. Seven hazards and their related risks were identified as being substantial or higher according to the Fine-Kinney method. Table 3 shows the hazards, their respective risk, and the risk scores as calculated using the Fine-Kinney method. 
Table 3 Hazards and associated risks in the substantial-risk and higher categories

\begin{tabular}{|c|c|c|c|c|}
\hline Hazard code & Definition & Risk code & Definition & Risk score \\
\hline Hazard $1(\mathrm{H} 1)$ & Lack of suitable fire extinguishers & Risk 1 (R1) & $\begin{array}{l}\text { Injury, death as a result of failure of fire extin- } \\
\text { guisher tubes }\end{array}$ & 80 \\
\hline Hazard $2(\mathrm{H} 2)$ & Failure of alarm and warning systems & Risk 2 (R2) & Injury, death in case of fire & 120 \\
\hline Hazard $3(\mathrm{H} 3)$ & Exposed electrical installation elements & Risk 3 (R3) & $\begin{array}{l}\text { Injury, death as a result of fire, sabotage, and } \\
\text { electric shock }\end{array}$ & 240 \\
\hline Hazard $4(\mathrm{H} 4)$ & $\begin{array}{l}\text { Unsuitable materials to fix electrical triple sockets } \\
\text { to the wall }\end{array}$ & Risk 4 (R4) & Injury, death as a result of electric shock & 120 \\
\hline Hazard 5 (H5) & Unauthorized access by non-employees & Risk 5 (R5) & Extortion, sabotage, robbery, injury, death & 120 \\
\hline Hazard 6 (H6) & Dangerous use and misuse of work equipment & Risk 6 (R6) & Injury, death as a result of fire and electric shock & 240 \\
\hline Hazard 7 (H7) & $\begin{array}{l}\text { Unsuitable materials in front of fire cabinets and } \\
\text { electrical panels }\end{array}$ & Risk 7 (R7) & $\begin{array}{l}\text { Injury, financial loss, death as a result of delayed } \\
\text { fire intervention }\end{array}$ & 120 \\
\hline
\end{tabular}

Table 4 Expert evaluations for the parameters

\begin{tabular}{llll}
\hline & Probability & Frequency & Severity \\
\hline Expert 1 & & & \\
Probability & - & $m$ & Between $v l$ and $l$ \\
Frequency & $m$ & - & $l$ \\
Severity & Between $h$ and $v h$ & $h$ & - \\
Expert 2 & & & \\
Probability & - & $v h$ & Between $m$ and $h$ \\
Frequency & $v l$ & - & $l$ \\
Severity & Between $l$ and $m$ & $h$ & - \\
Expert 3 & & & \\
Probability & - & $h$ & $v l$ \\
Frequency & $l$ & - & At most $v l$ \\
Severity & $v h$ & At least $v h$ & - \\
\hline & & &
\end{tabular}

\section{Determination of the weights of parameters and prioritization of hazards using HFLTS}

The parameter weights were determined using the multicriteria HFLTS method. Table 4 shows the linguistic evaluations of the experts for the parameters. Table 5 shows the envelopes obtained for each HFLTS. Table 6 shows the scale to be applied to the pessimistic and optimistic collective preference relations, where 0 indicates "no importance" and 6 indicates "absolute importance." Table 7 presents the pessimistic collective preference values, and Table 8 presents the optimistic collective preference values.

As an example, the pessimistic and optimistic collective preference values for $S$ in relation to $P$ are calculated using Eqs. (4) and (5), respectively.

$$
\begin{gathered}
P_{31}^{-}=\Delta\left(\frac{1}{3}\left(\Delta^{-1}(h, 4)+\Delta^{-1}(l, 2)+\Delta^{-1}(v h, 5)\right)\right) \\
\quad=\Delta\left(\frac{1}{3}(4+2+5)\right)=\Delta(3.67)=(h,-0.33)
\end{gathered}
$$

Table 5 Envelopes for HFLTS

\begin{tabular}{llll}
\hline & Probability & Frequency & Severity \\
\hline Expert 1 & & & \\
Probability & - & {$[m, m]$} & {$[v l, l]$} \\
Frequency & {$[m, m]$} & - & {$[l, l]$} \\
Severity & {$[h, v h]$} & {$[h, h]$} & - \\
Expert 2 & & & \\
Probability & - & {$[v h, v h]$} & {$[m, h]$} \\
Frequency & {$[v l, v l]$} & - & {$[l, l]$} \\
Severity & {$[l, m]$} & {$[h, h]$} & - \\
Expert 3 & & & {$[\mathrm{m}]$} \\
Probability & - & {$[h, h]$} & {$[n, v l]$} \\
Frequency & {$[l, l]$} & - & - \\
Severity & {$[v h, v h]$} & {$[v h, a]$} & \\
\hline
\end{tabular}

Table 6 The scale for HFLTS

\begin{tabular}{lllllll}
\hline$n$ & $v l$ & $l$ & $m$ & $h$ & $v h$ & $a$ \\
\hline 0 & 1 & 2 & 3 & 4 & 5 & 6 \\
\hline
\end{tabular}

Table 7 Pessimistic collective preferences

\begin{tabular}{llll}
\hline & Probability & Frequency & Severity \\
\hline Probability & - & $(h, 0)$ & $(l,-0.33)$ \\
Frequency & $(l, 0)$ & - & $(v l,+0.33)$ \\
Severity & $(h,-0.33)$ & $(h,+0.33)$ & - \\
\hline
\end{tabular}

Table 8 Optimistic collective preferences

\begin{tabular}{llll}
\hline & Probability & Frequency & Severity \\
\hline Probability & - & $(h, 0)$ & $(l,+0.33)$ \\
Frequency & $(l, 0)$ & - & $(l,-0.33)$ \\
Severity & $(h,+0.33)$ & $(v h,-0.33)$ & - \\
\hline
\end{tabular}


Table 9 Weights of the parameters

Table 10 Weights for the hazards

Table 11 Ranking obtained with S1

Table 12 Ranking obtained with S2

\begin{tabular}{lllll}
\hline Parameters & Linguistic intervals & Interval utilities & Midpoints & Weights \\
\hline Probability & {$[(m,-0.17),(m,+0.17)]$} & {$[(2.83),(3.17)]$} & 3.00 & 0.333 \\
Frequency & {$[(l,-0.33),(l,-0.17)]$} & {$[(1.67),(1.83)]$} & 1.75 & 0.195 \\
Severity & {$[(h, 0),(v h,-0.50)]$} & {$[(4.00),(4.50)]$} & 4.25 & 0.472 \\
\hline
\end{tabular}

\begin{tabular}{lllllllll}
\hline Parameter & Weight & \multicolumn{2}{l}{ Hazard } & & & & \\
\cline { 3 - 8 } & & H1 & H2 & H3 & H4 & H5 & H6 & H7 \\
\hline Probability & 0.333 & 0.028 & 0.044 & 0.063 & 0.041 & 0.050 & 0.067 & 0.040 \\
Frequency & 0.195 & 0.017 & 0.038 & 0.029 & 0.025 & 0.019 & 0.041 & 0.026 \\
Severity & 0.472 & 0.094 & 0.082 & 0.086 & 0.041 & 0.046 & 0.057 & 0.066 \\
Weight of hazards & & 0.139 & 0.164 & 0.178 & 0.107 & 0.115 & 0.165 & 0.132 \\
\hline
\end{tabular}

\begin{tabular}{llllllllll}
\hline Parameter & Weight & \multicolumn{2}{l}{ Hazard } & & & & \\
\cline { 3 - 9 } & & H1 & H2 & H3 & H4 & H5 & H6 & H7 \\
\hline Probability & 0.333 & 0.028 & 0.044 & 0.063 & 0.041 & 0.050 & 0.067 & 0.040 \\
Frequency & 0.333 & 0.030 & 0.064 & 0.049 & 0.043 & 0.033 & 0.070 & 0.044 \\
Severity & 0.333 & 0.066 & 0.058 & 0.061 & 0.029 & 0.033 & 0.040 & 0.046 \\
Weight of hazards & & 0.124 & 0.166 & 0.173 & 0.113 & 0.116 & 0.177 & 0.130 \\
\hline
\end{tabular}

\begin{tabular}{lllllllll}
\hline Parameter & Weight & \multicolumn{2}{l}{ Hazard } & & & & \\
\cline { 3 - 8 } & & H1 & H2 & H3 & H4 & H5 & H6 & H7 \\
\hline Probability & 0.333 & 0.028 & 0.044 & 0.063 & 0.041 & 0.050 & 0.067 & 0.040 \\
Frequency & 0.472 & 0.042 & 0.091 & 0.070 & 0.061 & 0.047 & 0.099 & 0.062 \\
Severity & 0.195 & 0.039 & 0.034 & 0.035 & 0.017 & 0.019 & 0.024 & 0.027 \\
Weight of hazards & & 0.109 & 0.169 & 0.168 & 0.119 & 0.116 & 0.190 & 0.129 \\
\hline
\end{tabular}

$$
\begin{aligned}
P_{31}^{+} & =\Delta\left(\frac{1}{3}\left(\Delta^{-1}(v h, 5)+\Delta^{-1}(m, 3)+\Delta^{-1}(v h, 5)\right)\right) \\
& =\Delta\left(\frac{1}{3}(5+3+5)\right)=\Delta(4.33)=(h,+0.33)
\end{aligned}
$$

Table 9 shows the weights of the parameters obtained from the values in Tables 7 and 8 . Table 9 indicates that Severity is the most significant parameter with a weight of 0.472 , whereas Frequency is the least important with a weight of 0.195 . The procedure was repeated for the hazards taking into account the parameter weights, and the weights of the seven hazards are shown in Table 10. H3 is the most important hazard, whereas $\mathrm{H} 4$ is the least important hazard. The order of priority of the hazards is $\mathrm{H} 3>\mathrm{H} 6>\mathrm{H} 2>\mathrm{H} 1$ $>\mathrm{H} 7>\mathrm{H} 5>\mathrm{H} 4$.

\section{Sensitivity analysis}

A sensitivity analysis was undertaken to investigate how a change in the weight of a parameter affects the ranking of the hazards. The value of each parameter weight was adjusted between two settings, and the hazards reassessed. Table 11 shows the results of Scenario 1 (S1), in which all criteria (parameters) were given an equal weight, and Table 12 shows the results of Scenario 2 (S2), in which the weight of the parameter with the highest weight (Severity) was swapped with the weight of the parameter with the lowest weight (Frequency).

\section{Results and discussion}

Figure 2 shows the ranking of the hazards for the original weights, $\mathrm{S} 1$ and $\mathrm{S} 2$. H3 is seen as the highest ranked hazard from the proposed method using the original weights. H6 is seen as the most important hazard for the two scenarios. For each scenario, $\mathrm{H} 2, \mathrm{H} 3$, and $\mathrm{H} 6$ remain the three most important hazards, and the ranking of $\mathrm{H} 5$ is unchanged. In general, as the weight of the severity parameter decreases, 


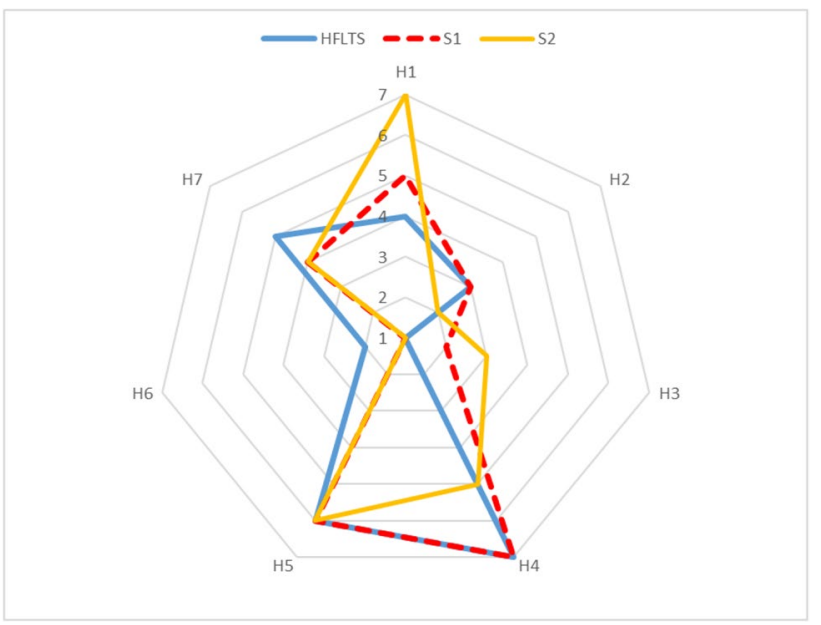

Fig. 2 Ranking of the hazards for original weights, S1 and S2

the importance of $\mathrm{H} 3$ decreases, and the importance of H6 increases.

These findings compare with those of Dağsuyu et al. (2016) and Gul et al. (2017). Dağsuyu et al. (2016) applied fuzzy FMEA for risk analysis in the sterilization unit of a hospital. Their results indicate that risks related to electric shock had high priority. Gul et al. (2017) applied the FAHPFVIKOR method for OHS risk assessment in a hospital. Their results also indicate that risk related to electricity was the most significant hazard in the emergency department.

\section{Mitigation of hazards}

The expert opinions gave the ranking of the hazards as: $\mathrm{H} 3>\mathrm{H} 6>\mathrm{H} 2>\mathrm{H} 1>\mathrm{H} 7>\mathrm{H} 5>\mathrm{H} 4$. The experience of the experts and the records of past incidents were then used to determine actions that should be taken to mitigate the risks associated with each hazard. These included:
- Electrical panel covers must be securely closed

- High power electric equipment such as electric heaters, tea makers, electric cookers should not be plugged into the same triple socket, and electrical extension cables should not be added to each other

- Periodic checks of alarm and warning systems should be made

- Periodic checks of fire extinguishers should be made

- The front of fire cabinets and electrical panels should be cleared, and placing material in these areas should be prohibited

- Security checks should be made at the entrances and exits during working hours

- Electrical extension cables should not be left on the floor and should be fixed to the wall or to the table with the equipment

Improvements were made in the unit in line with proposals for R3, R6, R7, R5, and R4, and a schedule for periodic checks for R2 and R1 was adopted.

\section{Mitigation for R3}

Figure 3 shows the covers of electrical panels were left open exposing live electrical components that presented a risk to employees. After mitigation, the covers of all electrical panels are kept closed and locked.

\section{Mitigation for R6}

Figure 4a shows an electric tea maker was plugged into the same triple wall socket as other high power electrical appliances. Figure $4 \mathrm{~b}$ shows multiple electrical extension cables were connected together resulting in overloaded sockets. Figure 5 shows the mitigation where triple wall sockets were replaced by multiple double sockets to prevent multiple high power appliances such as electric heaters, tea makers, and
Fig. 3 Mitigation for R3: Covers of all electrical panels are kept closed and locked

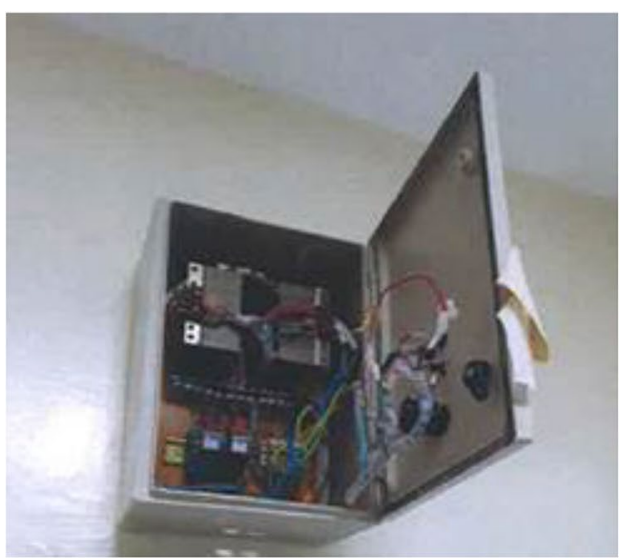

(a)

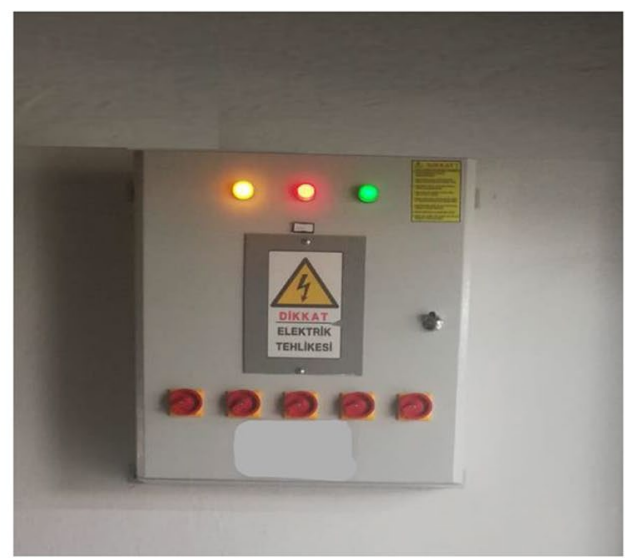

(b) 
Fig. 4 Mitigation for R6: (a) Multiple high power appliances plugged into the same triple wall socket. (b) Multiple extension sockets connected together
Fig. 5 Mitigation for R6: Triple wall socket replaced with extra double wall sockets to prevent high power appliances being plugged in the same triple socket, and extension cables removed and replaced by extra wall sockets

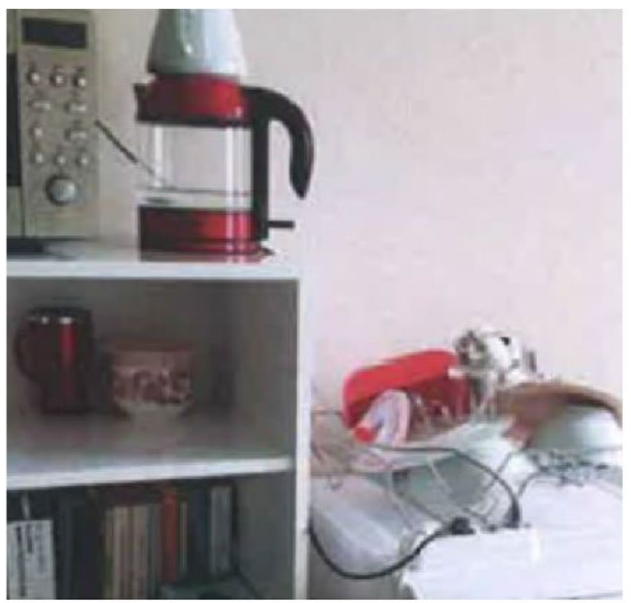

(a)

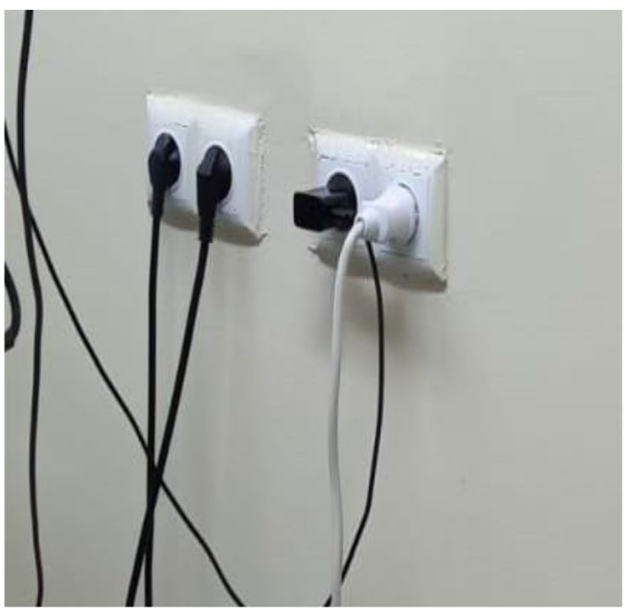

(a)

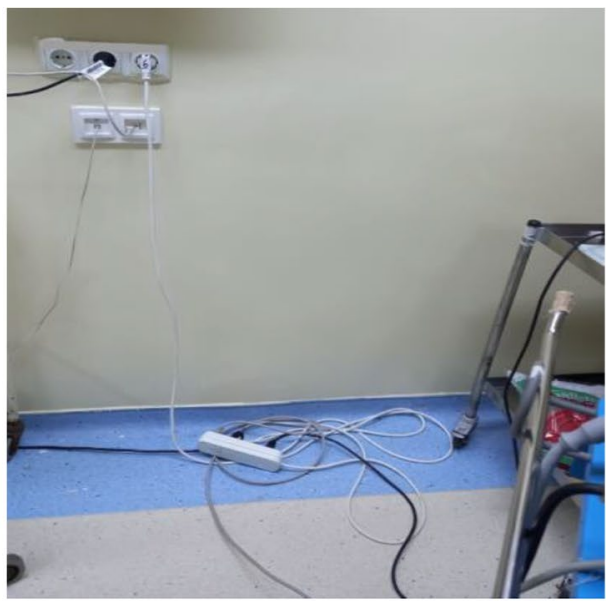

(b)

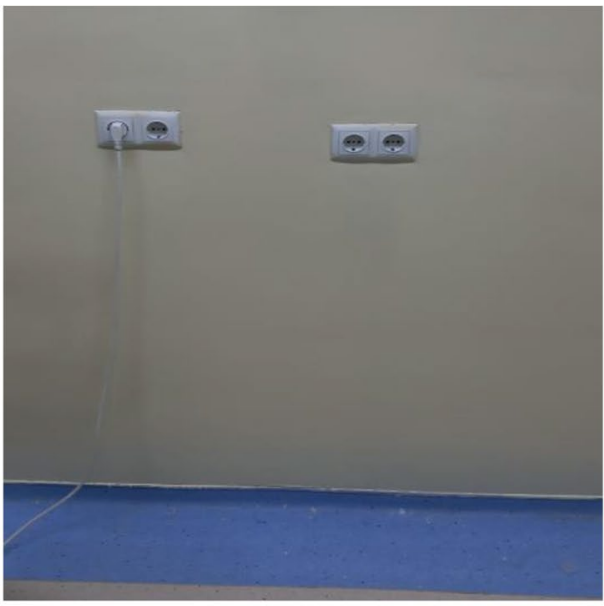

(b) electric stoves being plugged into the same triple socket. Extension electrical cables were replaced by multiple wall sockets and were only allowed to be used in places with the permission of an electrician.

\section{Mitigation for R7}

Figure 6a shows how all materials placed in front of fire cabinets and electrical panels were removed (Fig. 6b) to ensure unrestricted access to necessary equipment in case of emergency. Employees were informed that any material placed in front of a fire cabinets or electricals panel would be immediately removed.

\section{Mitigation for R5}

Access to the operating rooms by unauthorized persons was previously controlled by a security guard which proved inadequate in some instances. A card entry system (Fig. 7) was added in addition to having a security guard at each entrance.

\section{Mitigation for R4}

Unsuitable materials were used to fix electrical triple sockets, and extension sockets were left trailing on the floor (Fig. 8a) rather than being fixed to the wall. Extension sockets were fixed to the wall with suitable fasteners as shown in Fig. 8b.

\section{Conclusions and future works}

Unfavorable working conditions caused by technological developments and industrialization pose a threat to human health and safety in the workplace. In order to prevent 
Fig. 6 Mitigation for R7: All materials in front of electrical panels and fire cabinets removed

Fig. 7 Mitigation for R5:

Access to restricted areas controlled by card access in addition to a security guard at each entrance

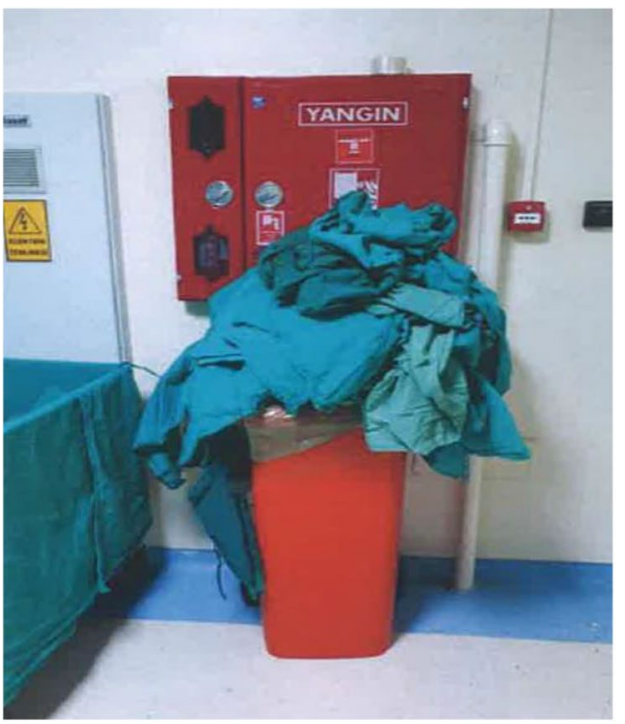

(a)

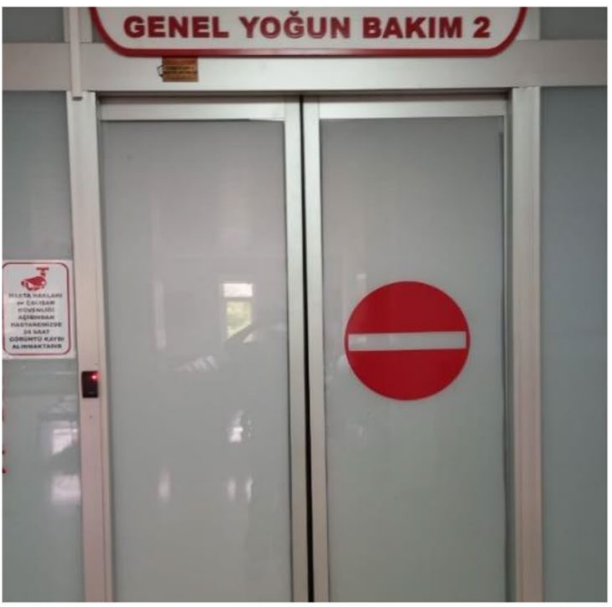

(a)

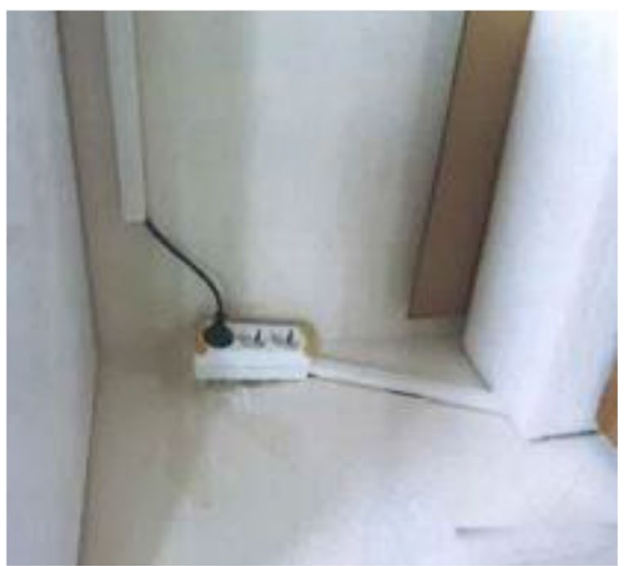

(a)

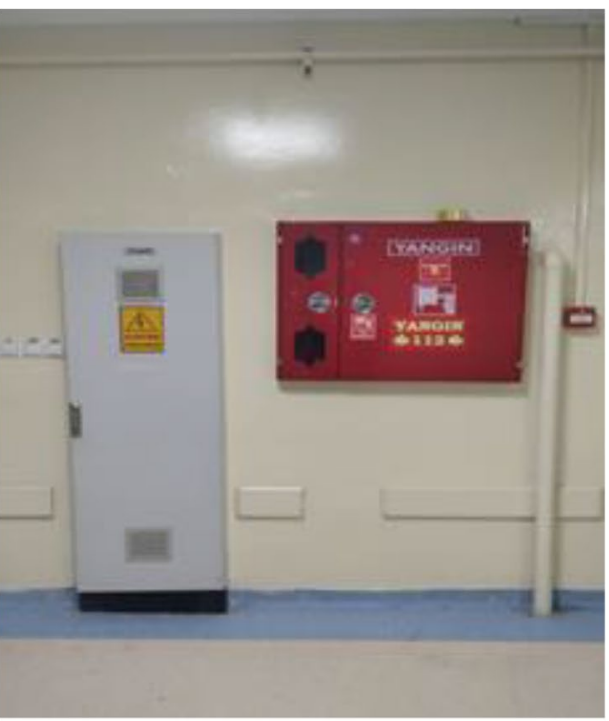

(b)

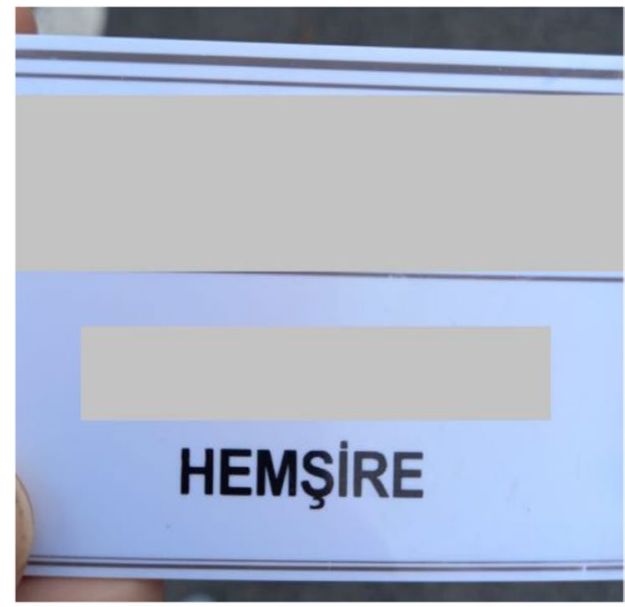

(b)

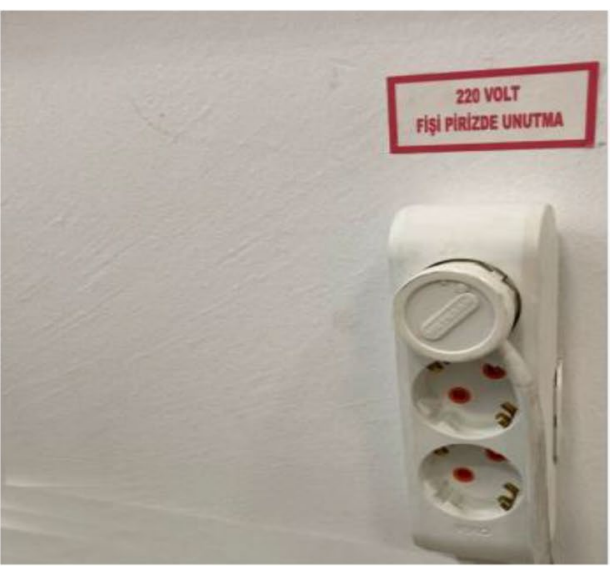

(b) 
occupational accidents and diseases that may occur in the workplace, a risk assessment should be made and protective and preventive measures taken to mitigate risks. This study, which presents a new approach to OHS risk assessment, combines the Fine-Kinney and multi-criteria HFLTS methods to identify hazards, and assess, prioritize, and mitigate risks. The proposed approach was applied to the operating room of a public hospital in Turkey. Three experts with responsibilities for OHS in the unit participated in the analysis process. The potential hazards and related risks in the operating room were first determined by the experts. Forty-four hazards were determined initially, and the risks were prioritized using the Fine-Kinney method. The parameter weights were then determined using the multi-criteria HFLTS method. Severity (S) was the most significant parameter with a weight of 0.472 , whereas Frequency $(\mathrm{F})$ was the least important parameter with a weight of 0.195 . The procedure was repeated for the seven hazards to be categorized as substantial-risk or higher according to the Fine-Kinney method, taking into account parameter weights. A sensitivity analysis was performed on the weights, and $\mathrm{H} 2, \mathrm{H} 3$, and $\mathrm{H} 6$ remained as the three most important hazards; the ranking of $\mathrm{H} 5$ was unchanged. The final stage was to determine and implement mitigation for the risks.

This study contributes to OHS risk assessment in two ways:

(1) The parameters in the Fine-Kinney method have equal weight, and so the risk scores can be equal, even though the values for the hazards differ. In this paper, the experts assign parameter weights to overcome this situation when using multi-criteria HFLTS.

(2) HFLTS provides a solution when experts hesitate between several linguistic expressions.

For future work, the methodology of this study can be applied in other units of the hospital. In addition, other types of fuzzy sets can be investigated, and the results compared.

Author contribution AÇB: conceptualization, methodology, validation, formal analysis, data curation, writing - original draft, writingreview and editing, visualization, supervision. AS: methodology, formal analysis, data curation, writing - original draft, writing-review and editing, visualization. This study was produced from the master's thesis of the second author under the supervision of the first author. It was carried out at the Ondokuz Mayis University, Institute of Graduate Studies, Department of Intelligent Systems Engineering in 2021.

Availability of data and material Not applicable.

\section{Declarations}

Ethics approval and consent to participate Not applicable.
Consent for publication Not applicable.

Competing interests The authors declare no competing interests.

\section{References}

Abad A, Gerassis S, Saavedra Á, Giráldez E, García JF, Taboada J (2019) A Bayesian assessment of occupational health surveillance in workers exposed to silica in the energy and construction industry. Environ Sci Pollut Res 26:29560-29569

Adem A, Çolak A, Dağdeviren M (2018) An integrated model using SWOT analysis and hesitant fuzzy linguistic term set for evaluation occupational safety risks in life cycle of wind turbine. Saf Sci 106:184-190

Bayatian M, Ashrafi K, Azari MR, Jafari MJ, Mehrabi Y (2018) Risk assessment of occupational exposure to benzene using numerical simulation in a complex geometry of a reforming unit of petroleum refinery. Environ Sci Pollut Res 25:11364-11375

Beg I, Rashid T (2013) TOPSIS for hesitant fuzzy linguisticterm sets. Int J Intell Syst 28:1162-1171

Büyüközkan G, Güler M (2020) Smart watch evaluation with integrated hesitant fuzzy linguistic SAW-ARAS technique. Measurement 153:107353

Büyüközkan G, Mukul E, Kongar E (2021) Health tourism strategy selection via SWOT analysis and integrated hesitant fuzzy linguistic AHP-MABAC approach. Socio-Econ Plan Sci 74:100929

Chang SC, Lin CF, Wu WM (2016) The features and marketability of certificates for occupational safety and health management in Taiwan. Saf Sci 85:77-87

Chen CY, Wu GS, Chuang KJ, Ma CM (2009) A comparative analysis of the factors affecting the implementation of occupational health and safety management systems in the printed circuit board industry in Taiwan. J Loss Prevent Proc 22:210-215

Chen ZS, Chin KS, Li YL, Yang Y (2016) Proportional hesitant fuzzy linguistic term set for multiple criteria group decision making. Inf Sci 357:61-87

Çalış Boyacı A (2020) Selection of eco-friendly cities in Turkey via a hybrid hesitant fuzzy decision making approach. Appl Soft Comput 89:106090

Çalış Boyacı A, Şişman A, Sarıcaoğlu K (2021) Site selection for waste vegetable oil and waste battery collection boxes: a GISbased hybrid hesitant fuzzy decision-making approach. Environ Sci Pollut Res 28:17431-17444

Da T, Xu YJ (2016) Evaluation on connectivity of urban waterfront redevelopment under hesitant fuzzy linguistic environment. Ocean Coast Manag 132:101-110

Dağsuyu C, Göçmen E, Narlı M, Kokangül A (2016) Classical and fuzzy FMEA risk analysis in a sterilization unit. Comput Ind Eng 101:286-294

Eurostat (2019) Accidents at work statistics, https://ec.europa.eu/euros tat/statistics-explained/index.php/Accidents_at_work_statistics. Accessed 29 Feb 2020

Fahmi A, Kahraman C, Bilen Ü (2016) Electre I method using hesitant linguistic term sets: an application to supplier selection. Int J Comput Intell Syst 9(1):153-167

Feng X, Tan Q, Wei C (2018) Hesitant fuzzy linguistic multi-criteria decision making based on possibility theory. Int J Mach Learn Cyber 9:1505-1517

Fine WT (1971) Mathematical evaluations for controlling hazards. Naval Ordnance Lab. White Oak, Maryland

Ghasemi P, Talebi Brijani E (2014) An integrated FAHP-PROMETHEE approach for selecting the best flexible manufacturing 
system. European Online Journal of Natural and Social Sciences 3(4):1137-1150

Ghorui N, Ghosh A, Mondal SP, Bajuri MY, Ahmadian A, Salahshour S, Ferrara M (2021) Identification of dominant risk factor involved in spread of COVID-19 using hesitant fuzzy MCDM methodology. Results Phys 21:103811

Gou XJ, Liao HC, Xu ZS, Herrera F (2017) Double hierarchy hesitant fuzzy linguistic term set and multimoora method: a case of study to evaluate the implementation status of haze controlling measures. Inf Fusion 38:22-34

Grassi A, Gamberini R, Mora C, Rimini B (2009) A fuzzy multi-attribute model for risk evaluation in workplaces. Saf Sci 47:707-716

Gul M, Ak MF (2018) A comparative outline for quantifying risk ratings in occupational health and safety risk assessment. J Clean Prod 196:653-664

Gul M, Ak MF (2020) Assessment of occupational risks from human health and environmental perspectives: a new integrated approach and its application using fuzzy BWM and fuzzy MAIRCA. Stoch Env Res Risk A 34:1231-1262

Gul M, Celik E (2018) Fuzzy rule-based Fine-Kinney risk assessment approach for rail transportation systems. Hum Ecol Risk Assess 24(7):1786-1812

Gul M, Ak MF, Güneri AF (2017) Occupational health and safety risk assessment in hospitals: a case study using two-stage fuzzy multicriteria approach. Hum Ecol Risk Assess Int J 23(2):187-202. https://doi.org/10.1080/10807039.2016.1234363

Gürcanli GE, Müngen U (2009) An occupational safety risk analysis method at construction sites usingfuzzy sets. Int J Ind Ergon 39:371-387

Health and Safety Authority (HSA) (2006) Guidelines on risk assessments and safety statements, Dublin, https://www.hsa.ie/eng/ Small_Business/Getting_Started/Risk_Assessments_Made_Easy/ Guidelines_on_Risk_Assessments_and_Safety_Statements.pdf. Accessed 28 May 2020

Huang J, You XY, Liu HC, Si SL (2019) New approach for quality function deployment based on proportional hesitant fuzzy linguistic term sets and prospect theory. Int J Prod Res 57(5):1283-1299

Ilbahar E, Karaşan A, Cebi S, Kahraman C (2018) A novel approach to risk assessment for occupational health and safety using Pythagorean fuzzy AHP \& fuzzy inference system. Saf Sci 103:124-136

İnan UH, Gül S, Y1lmaz H (2017) A multiple attribute decision model to compare the firms' occupational health and safety management perspectives. Saf Sci 91:221-231

Jalali M, Moghadam SR, Baziar M, Hesam G, Moradpour Z, Zakeri Hamid Reza, HR, (2021) Occupational exposure to formaldehyde, lifetime cancer probability, and hazard quotient in pathology lab employees in Iran: a quantitative risk assessment. Environ Sci Pollut Res 28:1878-1888

Khalilzadeh M, Ghasemi P, Afrasiabi A, Shakeri H (2021) Hybrid fuzzy MCDM and FMEA integrating with linear programming approach for the health and safety executive risks: a case study. J Model Manag. https://doi.org/10.1108/JM2-12-2019-0285

Khan MW, Ali Y, Felice FD, Petrillo A (2019) Occupational health and safety in construction industry in Pakistan using modified-SIRA method. Saf Sci 118:109-118

Khishtandar S, Zandieh M, Dorri B (2017) A multi criteria decision making framework for sustainability assessment of bioenergy production technologies with hesitant fuzzy linguistic term sets: the case of Iran. Renew Sustain Energy Rev 77:1130-1145

Kinney GF, Wiruth AD (1976) Practical risk analysis for safety management. Technical Publication, Naval Weapons Center, California

Kokangül A, Polat U, Dağsuyu C (2017) A new approximation for risk assessment using the AHP and Fine Kinney methodologies. Saf Sci 91:24-32
Larsson TJ, Field B (2002) The distribution of occupational injury risks in the state of Victoria. Saf Sci 40:419-437

Leigh JP, Miller TR (1998) Job-related diseases and occupations within a large workers' compensation data set. Am J Ind Med 33:197-211

Liao HC, Xu ZS (2015) Approaches to manage hesitant fuzzy linguistic information based on the cosine distance and similarity measures for hfltss and their application in qualitative decision making. Expert Syst Appl 42:5328-5336

Liao HC, Yang LY, Xu ZS (2018) Two new approaches based on ELECTREII to solve the multiple criteria decision making problems with hesitant fuzzy linguistic term sets. Appl Soft Comput 63:223-234

Liao HC, Xu ZS, Zeng XJ (2014) Distance and similarity measures for hesitant fuzzy linguistic term sets and their application in multi-criteria decision making. Inf Sci 271:125-142

Liu HC, Fan XJ, Li P, Chen YZ (2014) Evaluating the risk of failure modes with extended MULTIMOORA method under fuzzy environment. Eng Appl Artif Intel 34:168-177

Liu R, Hou LX, Liu HC, Lin W (2020) Occupational health and safety risk assessment using an integrated SWARA-MABAC model under bipolar fuzzy environment. Comput Appl Math 39:276

Liu HB, Rodríguez RM (2014) A fuzzy envelope for hesitant fuzzy linguistic term set and its application to multicriteria decision making. Inf Sci 258:220-238

Liu HT, Tsai YL (2012) A fuzzy risk assessment approach for occupational hazards in the construction industry. Saf Sci 50:1067-1078

Liu HC, You JX, Li P, Su Q (2016) Failure mode and effect analysis under uncertainty: an integrated multiple criteria decision making approach. IEEE Trans Reliab 65(3):1380-1392

Liu R, Zhu Y-J, Chen Y, Liu H-C (2021) Occupational health and safety risk assessment using an integrated TODIM-PROMETHEE model under linguistic spherical fuzzy environment. Int J Intell Syst 36:6814-6836

Macedo AC, Silva IL (2005) Analysis of occupational accidents in Portugal between 1992 and 2001. Saf Sci 43:269-286

Mahdevari S, Shahriar K, Esfahanipour A (2014) Human health and safety risks management in underground coal mines using fuzzy TOPSIS. Sci Total Environ 488-489:85-99

MMO (2018) İşçi sağlı̆̆ ve iş güvenliği, https://www.mmo.org.tr/kitap lar/isci-sagligi-ve-guvenligi-1. Accessed 20 Aug 2020

Mohammadyan M, Moosazadeh M, Borji A, Khanjani N, Rahimi Moghadam S, Behjati Moghadam AM (2019a) Health risk assessment of occupational exposure to styrene in Neyshabur electronic industries. Environ Sci Pollut Res 26:11920-11927

Mohammadyan M, Moosazadeh M, Khanjani N, Rahimi Moghadam S (2019b) Quantitative and semi-quantitative risk assessment of occupational exposure to lead among electrical solderers in Neyshabur. Iran Environ Sci Pollut Res 26:31207-31214

Mohandes SR, Zhang X (2019) Towards the development of a comprehensive hybrid fuzzy-based occupational risk assessment model for construction worker. Saf Sci 115:294-309

Morillas RM, Rubio-Romero JC, Fuertes A (2013) A comparative analysis of occupational health and safety risk preventionpractices in Sweden and Spain. J Safety Res 47:57-65

Montes R, Sánchez AM, Villar P, Herrera F (2015) A web tool to support decision making in the housing market using hesitant fuzzy linguistic term sets. Appl Soft Comput 35:949-957

Murè S, Demichela M, Piccinini N (2006) Assessment of the risk of occupational accidents using a "fuzzy" approach. Cogn Tech Work 8:103-112

Onar SÇ, Büyüközkan G, Öztayşi B, Kahraman C (2016) A new hesitant fuzzy QFD approach: an application to computer workstation selection. Appl Soft Comput 46:1-16 
Rachidi H, Hamdaoui S, Merimi I, Bengourram J, Latrache H (2021) COVID-19: unbalanced management of occupational risks-case of the analysis of the chemical risk related to the use of disinfectants in the dairy industry in Morocco. Environ Sci Pollut Res. https://doi.org/10.1007/s11356-021-13846-1

Rodríguez RM, Martinez L, Herrera F (2012) Hesitant fuzzy linguistic term sets for decision making. IEEE Trans Fuzzy Syst 20(1):109-119

Rodríguez RM, Labella A, Sesma-Sara M, Bustince H, Martínez L (2021) A cohesion-driven consensus reaching process for large scale group decision making under a hesitant fuzzy linguistic term sets environment. Computers \& Industrial Engineering $155: 107158$

Rodríguez RM, Martínez L, Herrera F (2013) A group decision making model dealing with comparative linguistic expressions based on hesitant fuzzy linguistic term sets. Inf Sci 241:28-42

Sousa V, Almeida NM, Dias LA (2015) Risk-based management of occupational safety and health in the construction industry-Part 2: quantitative model. Saf Sci 74:184-194

Stefanović V, Urošević S, Mladenović-Ranisavljević I, Stojilković P (2019) Multi-criteria ranking of workplaces from the aspect of risk assessment in the production processes in which women are employed. Saf Sci 116:116-126

Tang J, Liu X, Wang W (2021) A hybrid risk prioritization method based on generalized TODIM and BWM for Fine-Kinney under interval type-2 fuzzy environment. Hum Ecol Risk Assess 27(4):954-979
Torra V (2010) Hesitant fuzzy sets. Int J Intell Syst 25:529-539

Tüysüz F, Şimşek B (2017) A hesitant fuzzy linguistic term sets based AHP approach for analyzing the performance evaluation factors: an application to cargo sector. Complex Intell Syst 3:167-175

Wang J, Qian W, Du J, Liu Y (2020) Effective allocation of resources in water pollution treatment alternatives: a multi-stage gray group decision-making method based on hesitant fuzzy linguistic term sets. Environ Sci Pollut Res 27:3173-3186

Wang J, Wang JQ, Zhang HY, Chen XH (2015) Multi-criteria decisionmaking based on hesitant fuzzy linguistic term sets: an outranking approach. Knowl Based Syst 86:224-236

Wei C, Ren Z, Rodríguez RM (2015) A hesitant fuzzy linguistic todim method based on a score function. Int J Comput Intell Syst 8(4):701-712

Wu Z, Xu J, Jiang X, Zhong L (2019) Two MAGDM models based on hesitant fuzzy linguistic term sets with possibility distributions: VIKOR and TOPSIS. Inf Sci 473:101-120

Yavuz M, Öztayşi B, Onar SÇ, Kahraman C (2015) Multi-criteria evaluation of alternative-fuel vehicles via a hierarchical hesitant fuzzy linguistic model. Expert Syst Appl 42:2835-2848

Publisher's note Springer Nature remains neutral with regard to jurisdictional claims in published maps and institutional affiliations. 